\title{
Safety and efficacy of sucroferric oxyhydroxide in pediatric patients with chronic kidney disease
}

\author{
Larry A. Greenbaum ${ }^{1}$ (D) Nikola Jeck ${ }^{2} \cdot{\text { Günter } \text { Klaus }^{2} \cdot \text { Marc Fila }^{3} \cdot \text { Cristina Stoica }^{4} \cdot \text { Sahar Fathallah-Shaykh }}^{5}$. \\ Ana Paredes ${ }^{6} \cdot$ Larysa Wickman $^{7} \cdot$ Raoul Nelson $^{8} \cdot$ Rita D. Swinford ${ }^{9}$. Carolyn Larkins Abitbol ${ }^{10}$ (D) \\ Mihaela Balgradean $^{11} \cdot$ Augustina Jankauskiene $^{12}$ (D) . Amandine Perrin ${ }^{13} \cdot$ Milica Enoiu $^{13} \cdot$ Sun-Young Ahn ${ }^{14}$ (D)
}

Received: 1 January 2020 / Revised: 8 September 2020 / Accepted: 30 September 2020 / Published online: 27 October 2020

(C) The Author(s) 2020

\begin{abstract}
Background Pediatric patients with advanced chronic kidney disease (CKD) are often prescribed oral phosphate binders (PBs) for the management of hyperphosphatemia. However, available PBs have limitations, including unfavorable tolerability and safety.

Methods This phase 3, multicenter, randomized, open-label study investigated safety and efficacy of sucroferric oxyhydroxide (SFOH) in pediatric and adolescent subjects with CKD and hyperphosphatemia. Subjects were randomized to SFOH or calcium acetate (CaAc) for a 10-week dose titration (stage 1), followed by a 24-week safety extension (stage 2). Primary efficacy endpoint was change in serum phosphorus from baseline to the end of stage 1 in the SFOH group. Safety endpoints included treatmentemergent adverse events (TEAEs).

Results Eighty-five subjects (2-18 years) were randomized and treated (SFOH, $n=66$; CaAc, $n=19)$. Serum phosphorus reduction from baseline to the end of stage 1 in the overall SFOH group (least squares [LS] mean \pm standard error [SE]) was $-0.488 \pm 0.186 \mathrm{mg} /$ $\mathrm{dL} ; p=0.011$ (post hoc analysis). Significant reductions in serum phosphorus were observed in subjects aged $\geq 12$ to $\leq 18$ years (LS mean $\pm \mathrm{SE}-0.460 \pm 0.195 \mathrm{mg} / \mathrm{dL} ; p=0.024)$ and subjects with serum phosphorus above age-related normal ranges at baseline (LS mean $\pm \mathrm{SE}-0.942 \pm 0.246 \mathrm{mg} / \mathrm{dL} ; p=0.005)$. Similar proportions of subjects reported $\geq 1 \mathrm{TEAE}$ in the $\mathrm{SFOH}(75.8 \%)$ and CaAc (73.7\%) groups. Withdrawal due to TEAEs was more common with CaAc (31.6\%) than with SFOH (18.2\%).

Conclusions SFOH effectively managed serum phosphorus in pediatric patients with a low pill burden and a safety profile consistent with that reported in adult patients.
\end{abstract}

Keywords Chronic kidney disease $\cdot$ Hyperphosphatemia $\cdot$ Children $\cdot$ Phosphate binder $\cdot$ Sucroferric oxyhydroxide $\cdot$ Safety profile

Electronic supplementary material The online version of this article (https://doi.org/10.1007/s00467-020-04805-y) contains supplementary material, which is available to authorized users.

Larry A. Greenbaum

lgreen6@emory.edu

1 Division of Pediatric Nephrology, Emory University School of Medicine and Children's Healthcare of Atlanta, 2015 Uppergate Drive NE, Atlanta, GA 30322, USA

2 KfH Pediatric Kidney Center and Department of Pediatrics II, Philipps-University, Marburg, Germany

3 CHU Hôpital Arnaud de Villeneuve, Montpellier, France

4 Institutul Clinic Fundeni, Bucharest, Romania

5 University of Alabama at Birmingham, Birmingham, AL, USA

6 Nicklaus Children's Hospital, Miami, FL, USA
7 C.S Mott Children's Hospital, Michigan Medicine, Ann Arbor, MI, USA

8 University of Utah, Salt Lake City, UT, USA

9 The University of Texas Medical School at Houston, Houston, TX, USA

10 University of Miami - Miller School of Medicine, Miami, FL, USA

11 UMF 'Carol Davila' Spitalul Clinic de Urgență pentru copii "Maria Sklodowska Curie”, Bucharest, Romania

12 Vilnius University hospital Santaros klinikos, Vilnius University, Vilnius, Lithuania

13 Vifor Pharma Management Ltd., Glattbrugg, Switzerland

14 Children's National Hospital, The George Washington University, Washington, DC, USA 


\section{Introduction}

Hyperphosphatemia is a common complication in patients with chronic kidney disease (CKD) [1, 2], particularly those with kidney failure, in whom elevated serum phosphorus has been identified as a risk factor for mortality, morbidity, and hospitalizations [3-5]. Hyperphosphatemia contributes to several CKD complications, including secondary hyperparathyroidism [6], mineral and bone disorder (MBD) [7], and development of cardiovascular disease [3, 8]. Optimal management of hyperphosphatemia is particularly important in pediatric CKD patients for prevention of skeletal abnormalities and growth impairment, as well as for preservation of long-term cardiovascular health [9].

Dietary phosphate restriction alone rarely provides adequate serum phosphorus control in advanced $\mathrm{CKD}$, and severe restriction in pediatric patients may adversely impact the patient's growth and development by limiting protein intake [10]. In addition, the use of dialysis for the removal of excess phosphate is not very effective, as phosphate is mainly stored intracellularly. Many CKD patients, therefore, require treatment with oral phosphate binders (PBs) to inhibit gastrointestinal (GI) absorption of dietary phosphate [6].

PBs are widely prescribed to pediatric patients with advanced CKD, though not all of these agents are approved for this indication. Calcium-based PBs, including calcium acetate and calcium carbonate, have been extensively studied in pediatric CKD [11, 12], but are associated with a risk of hypercalcemia and vascular calcification [13-15]. Non-calcium PB options include sevelamer and lanthanum carbonate. Sevelamer is a non-metallic anion-exchange resin available as a carbonate or hydrochloride salt $[16,17]$. Sevelamer carbonate is the only non-calcium-based PB currently approved for use in pediatric CKD patients (6 years and older) [17]. Although sevelamer effectively reduces serum phosphorus levels, it has a relatively high pill burden when taken in tablet form, requires swallowing of large tablets without chewing, and is associated with GI side effects, all of which may contribute to poor compliance. The powder form of sevelamer carbonate also requires a large dose that may decrease compliance. In addition, sevelamer may also reduce the GI absorption of fat-soluble vitamins [16, 17]. Lanthanum carbonate is a potent phosphate binder that provides effective serum phosphorus control, with a low daily pill burden. However, the observed deposition of lanthanum in several organs (e.g., bone, liver) has raised potential toxicity concerns about its use [18-20]. Given the limitations of the available calciumand non-calcium PB therapies, new effective agents with good safety and tolerability profiles are needed for the treatment of hyperphosphatemia in both adult and pediatric CKD patients.

Sucroferric oxyhydroxide (SFOH) is an iron-based $\mathrm{PB}$ with a low pill burden indicated for the treatment of hyperphosphatemia in adult dialysis patients. Clinical studies in adults have demonstrated that $\mathrm{SFOH}$ is well tolerated and provides effective long-term serum phosphorus control [21-23]. However, there are no data relating to its safety and efficacy in children with CKD.

The aim of this clinical study was to investigate the safety and efficacy of SFOH in pediatric and adolescent patients with $\mathrm{CKD}$ and to provide dosing information for this patient population.

\section{Methods}

\section{Study design}

This was a phase 3 , multicenter, randomized, prospective, open-label, active-controlled trial conducted in 41 centers in 7 countries (24 centers in the United States [US], 17 in Europe). The study design is shown in Fig. 1. Following a screening period of up to 4 weeks, and a washout period of up to 3 weeks (for participants previously taking PBs with a serum phosphorus below the age-specific target range), eligible subjects were randomized to $\mathrm{SFOH}$ or calcium acetate $(\mathrm{CaAc})$ for a dose titration period of up to 10 weeks (stage 1 ), followed by a 24 -week safety extension (stage 2). All randomized subjects were followed for 14 days after their last study visit. The study planned to randomize approximately 130 subjects to receive either SFOH ( $\sim 100$ subjects) or the active comparator, CaAc ( $\sim 30$ subjects). Randomization was stratified by age group $(0$ to $<1$ year, $\geq 1$ to $<6$ years, $\geq 6$ to $<$ 9 , and $\geq 9$ to $<18$ years) and aimed to randomize minimum numbers of subjects per age group. The study (ClinicalTrials. gov: NCT02688764) was approved by the institutional review boards at each participating center, was conducted in accordance with the Declaration of Helsinki principles [24], and was in compliance with the International Council for Harmonization (ICH) E6 Guideline for Good Clinical Practice (GCP) [25], and with regulations applicable in the respective countries. All subjects or their parents/legal guardians provided written informed consent/assent prior to any study-specific procedures. An independent Data and Safety Monitoring Board was constituted to protect the safety of study participants.

\section{Study participants and assessments}

The study enrolled subjects with CKD and hyperphosphatemia defined according to age-specific criteria, as detailed in Fig. 1. Eligible subjects were either PB-naïve or had been receiving stable doses of a maximum of two PBs for at least 1 month prior to screening. Subjects receiving prior PB therapy with serum 


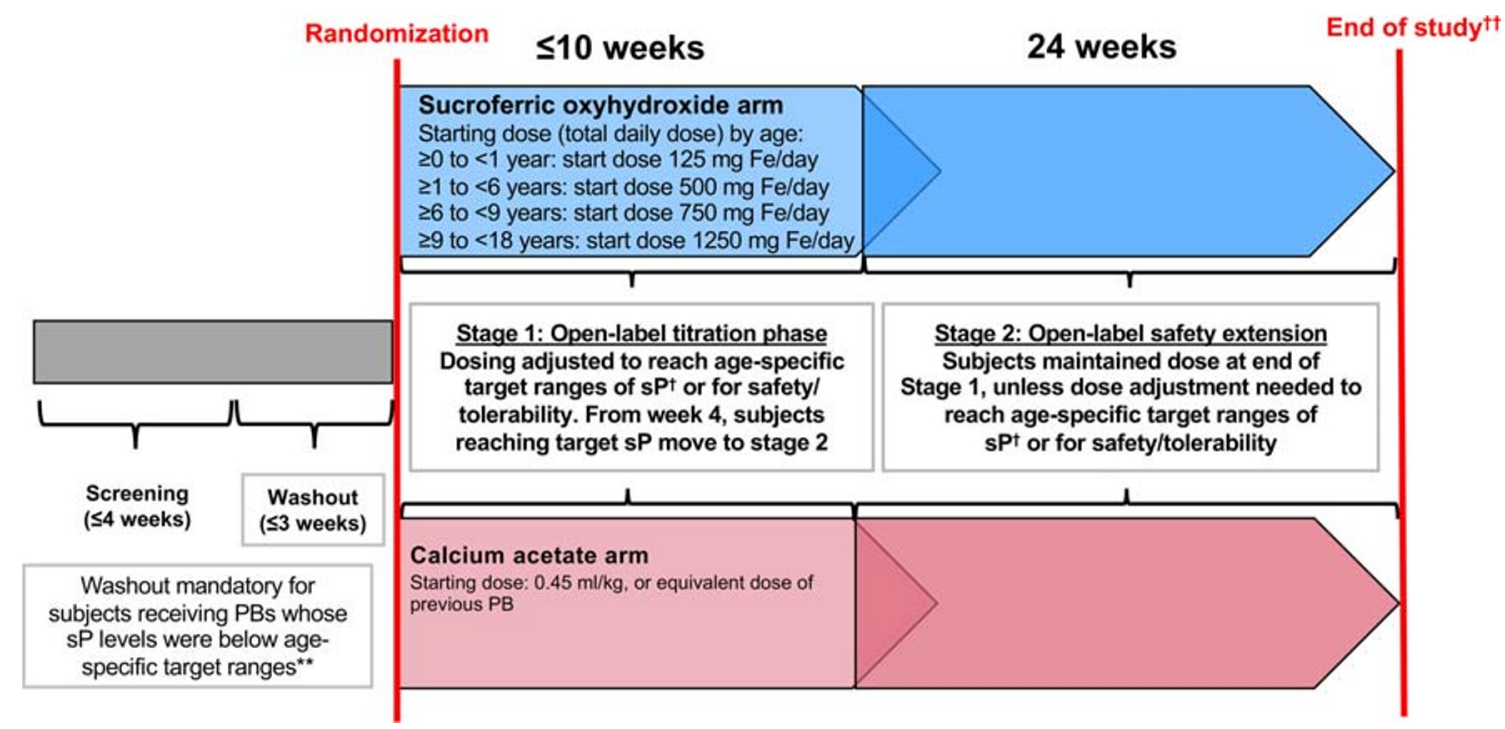

Fig. 1 Study design. **Age-related $\mathrm{sP}$ targets for washout period 0 to $<$ 6 months, $>8.1 \mathrm{mg} / \mathrm{dL} ; \geq 6$ months to $<1$ year, $>7.1 \mathrm{mg} / \mathrm{dL} ; \geq 1$ year to $<6$ years, $>6.3 \mathrm{mg} / \mathrm{dL} ; \geq 6$ years to $<13$ years, $>5.5 \mathrm{mg} / \mathrm{dL} ; \geq 13$ years to $<18$ years, $>4.2 \mathrm{mg} / \mathrm{dL}{ }^{\dagger}$ Age-related sP targets post-randomization 0 to

phosphorus below the age-specific target were required to undergo a washout period before randomization. Subjects already receiving a $\mathrm{PB}$ whose serum phosphorus levels met age-specific target levels were eligible for randomization without a washout; prior PBs were discontinued. All subjects were required to have $\mathrm{CKD}$ and subjects $\geq 1$ year old were required to have stage 4 or $5 \mathrm{CKD}$ defined by an estimated glomerular filtration rate $(\mathrm{eGFR})<30 \mathrm{~mL} / \mathrm{min} /$ $1.73 \mathrm{~m}^{2}$ [26], or stage 5D CKD on at least 2 months of adequate maintenance hemodialysis (HD) or peritoneal dialysis (PD) before screening. As far as possible, dialysis regimens were not changed during the study. Concomitant medications that may influence serum phosphorus (e.g., vitamin $\mathrm{D}$, vitamin $\mathrm{D}$ analogues and calcimimetics), were, per protocol, not changed as far as possible during the study. Counseling regarding dietary phosphorus per local practice was encouraged.

Exclusion criteria included hypercalcemia (per age-specific definition), hypocalcemia (serum total corrected calcium < $7.6 \mathrm{mg} / \mathrm{dL}$ at screening), and intact parathyroid hormone (iPTH) $>700 \mathrm{pg} / \mathrm{mL}$ at screening. A full list of exclusion criteria is provided in Supplementary Table 1.

A schedule of study visits and associated assessments is provided in Supplementary Fig. 1. Following randomization, treatment period visits took place at weeks 1, 2, 4, 6, 8 , and 10 (stage 1), and at weeks 14, 18, 22, 28, and 34 (stage 2) after the baseline visit. For HD subjects, blood samples were obtained prior to a HD session and study visits were planned after a maximum interdialytic period of $48 \mathrm{~h}$ and on the same day and same session each week, as far as possible. Blood samples were analyzed by the central laboratory whenever possible.
1 year, $5.0-7.8 \mathrm{mg} / \mathrm{dL} ; \geq 1$ year to $<6$ years, $4.5-6.5 \mathrm{mg} / \mathrm{dL} ; \geq 6$ years to $<13$ years, $3.6-5.8 \mathrm{mg} / \mathrm{dL} ; \geq 13$ years to $<18$ years, $2.3-4.5 \mathrm{mg} / \mathrm{dL}$ [27].

${ }^{\dagger}$ All subjects (including withdrawn) followed for 14 days after the last study visit. PBs, phosphate binders; $\mathrm{sP}$, serum phosphorus

\section{Randomization and study treatments}

Eligible subjects were randomized to treatment with $\mathrm{SFOH}$ or $\mathrm{CaAc}$ at the baseline visit; other PBs were discontinued and prohibited during the study. SFOH was provided in two formulations: a formulated powder for oral suspension (doses corresponding to 125,250 , and $500 \mathrm{mg}$ of iron) in sachet packs for subjects $<6$ years old, and chewable tablets (doses corresponding to 250 and $500 \mathrm{mg}$ of iron) for subjects $\geq 6$ years old. Because of the possibility of dose changes at increments of $125 \mathrm{mg} /$ day among subjects 6-9 years old, this age group would ideally receive formulated powder for oral suspension. Although the formulated powder for oral suspension is not an ideal pharmaceutical composition, it has been considered as an appropriate option for the pediatric population. During stage $1, \mathrm{SFOH}$ was administered at an age-dependent starting dose, and titrated in increments of 125 to $500 \mathrm{mg}$ iron/day, based on subject age (Supplementary Table 2). Subjects randomized to CaAc received a starting dose of $0.45 \mathrm{~mL} / \mathrm{kg} /$ day of an oral solution containing $667 \mathrm{mg}$ of CaAc per $5 \mathrm{~mL}$ (Phoslyra; Lyne Laboratories Inc., Brockton, MA 02301, USA), or an equivalent dose of their previous PB (calcium-based or sevelamer) if the investigator considered this more appropriate. CaAc was titrated in increments of 0.1 to $0.2 \mathrm{~mL} / \mathrm{kg} /$ day (maximum dose of $1.25 \mathrm{~mL} / \mathrm{kg}$ /day up to $35 \mathrm{~kg}$, and $44 \mathrm{~mL} /$ day if $>35 \mathrm{~kg}$ ).

Subsequently, doses of $\mathrm{SFOH}$ or $\mathrm{CaAc}$ were titrated as required for efficacy (to achieve age-specific target serum phosphorus levels (Fig. 1), provided a subject had been receiving a stable dose for a minimum of 2 weeks) [27]. From week 4 onwards, subjects who achieved the age-specific target serum phosphorus level could enter stage 2 of the study, where they continued receiving the same dose of $\mathrm{SFOH}$ or CaAc. 


\section{Analysis populations}

The safety population included all subjects who received $\geq 1$ dose of study medication. The full analysis set (FAS) included all subjects randomized to treatment at stage 1 who received $\geq$ 1 dose of randomized treatment and who had at least 1 postbaseline assessment of the efficacy endpoint (serum phosphorus level). The per protocol set (PPS) included all subjects in the FAS who had no major protocol deviations. The FAS was the primary population for the analyses of efficacy and was also used for analyses of baseline characteristics. A subset of efficacy parameters was evaluated for the PPS population.

\section{Study outcomes}

The primary efficacy endpoint was change in serum phosphorus levels from baseline to the end of stage 1 in the SFOH group. Secondary efficacy endpoints included change in serum phosphorus from baseline to the end of stage 1 in the CaAc group, and to the end of stage 2 in the $\mathrm{SFOH}$ and $\mathrm{CaAc}$ groups. Serum phosphorus values at each visit during stage 1 and 2, and percentage of subjects with serum phosphorus levels within the agedependent target range, or within the age-dependent normal range at each visit were also evaluated.

Primary safety endpoints were the adverse event (AE) profile and the percentage of withdrawals due to AEs. Secondary safety endpoints included serum total corrected calcium over time; percentage of subjects who developed $\geq 1$ episode of sustained hypercalcemia (elevated serum calcium confirmed by repeat sample 1 week later) after start of treatment; serum iPTH levels over time; and routine clinical laboratory tests.

\section{Sample size calculation and statistical analysis}

\section{Sample size calculation}

In the $\mathrm{SFOH}$ treatment group, assuming a mean \pm standard deviation (SD) change in serum phosphorus from baseline to end of stage 1 of $1.2 \pm 2.0 \mathrm{mg} / \mathrm{dL}$, and further allowing for an estimated dropout rate of 30\%, 100 randomized subjects would provide more than $90 \%$ power to detect a significant change in serum phosphorus levels from baseline to the end of stage 1 . One hundred $(n=100)$ subjects were also considered sufficient to provide robust safety and dosing information for $\mathrm{SFOH}$ in pediatric and adolescent subjects with CKD.

\section{Primary efficacy endpoint analyses}

The primary endpoint was based on central laboratory data; in case of missing data, the change from baseline was to be computed using pre- and post-treatment values from the local laboratory. Change from baseline was analyzed using a predefined linear mixed model, with treatment, baseline serum phosphorus, age at randomization (by category), geographic region (US and non-US), and gender as fixed effects. To account for imbalance in the age group covariate, a post hoc analysis was performed using a linear mixed model that included the same fixed effects as described above, but with age at randomization as a continuous variable. Summary statistics, with the estimate of the adjusted mean change from baseline and its $95 \%$ confidence interval $(95 \% \mathrm{CI})$, as well as the corresponding $p$ value ( $t$ test), were provided.

Sensitivity analyses included a repeat of the main analysis based on observed data from the central laboratory only (with no imputation using local laboratory data). Homogeneity of the primary endpoint findings was investigated through analysis of change from baseline in subgroups defined by age at randomization, serum phosphorus at baseline according to the age-related normal range, and the combination of age at randomization and serum phosphorus at baseline according to the age-related normal range.

\section{Secondary efficacy endpoint analyses}

Secondary efficacy endpoints related to the change from baseline in serum phosphorus were analyzed using the same predefined linear mixed model as for the primary efficacy endpoint; in addition, a post hoc analysis was performed as described above. Overall compliance, based on doses taken relative to the number expected to be taken, according to drug dispensing/return records, was summarized using descriptive statistics.

\section{Safety analyses}

Treatment-emergent adverse events (TEAEs) were summarized for both treatment groups (subject incidence rates and total number of events). Medical history and adverse events were coded using the Medical Dictionary for Regulatory Activities (version 19.1). For laboratory parameters, absolute values and changes from baseline values, based on central laboratory data, were summarized separately at each time point by treatment group. The percentage of subjects who developed $\geq 1$ episode of sustained hypercalcemia after the start of treatment was summarized by treatment group.

\section{General statistical methods}

All descriptive statistical analyses were performed using Statistical Analysis System ${ }^{\circledR}$ statistical software (version 9.4). Formal statistical hypothesis testing was performed on the primary efficacy endpoint only, at a two-sided significance level of 0.05 . 


\section{Results}

\section{Patient disposition and analysis sets}

Patient disposition (stage 1 and stage 2) is shown in Fig. 2. There were 85 subjects in the safety population $(n=66$ $[\mathrm{SFOH}]$ and $n=19[\mathrm{CaAc}]$ ) and 80 subjects in the FAS, which was the primary population for efficacy analysis $(n=65$ $[\mathrm{SFOH}]$ and $n=15[\mathrm{CaAc}])$. Major protocol deviations, mainly involving compliance with study treatment, were identified in $23(35.4 \%)$ subjects in the SFOH group and $10(66.7 \%)$ subjects in the CaAc group. Therefore, only 47 subjects were included in the PPS population $(n=42[\mathrm{SFOH}]$ and $n=5$ $[\mathrm{CaAc}])$. Baseline demographic and disease characteristics were generally comparable between treatment groups in the FAS (Table 1). Ages of subjects in the FAS ranged from 2 to $\leq 18$ years and the majority $(67.5 \%)$ were receiving HD. In both treatment groups, there was an imbalance in patient age group categories. Adolescents ( $12-\leq 18$ years) comprised the majority of subjects treated with $\mathrm{SFOH}$ or $\mathrm{CaAc}(64.6 \%$ and $66.7 \%$, respectively), whereas subjects aged $6-<12$ years $(26.2 \%$ and $26.7 \%)$ or $2-<6$ years $(9.2 \%$ and $6.7 \%)$ accounted for smaller proportions.

\section{Primary efficacy endpoint results}

In the overall FAS, the reduction in serum phosphorus from baseline to the end of stage 1 in the SFOH group, analyzed with the pre-defined statistical model, was not statistically significant $(p=0.146)$ : least squares (LS) mean \pm standard error (SE) of $-0.371 \pm 0.251 \mathrm{mg} / \mathrm{dL}$ (95\% CI $0.874,0.132$ ) (Table 2). Similar results were observed from the sensitivity analysis without imputation of missing central laboratory values (data not shown), and analysis of the PPS population (Table 2). However, a post hoc analysis, accounting for imbalance in the age group covariate, showed a statistically significant reduction in serum phosphorus from baseline to the end of stage 1 in the overall FAS: LS mean \pm SE of $-0.488 \pm$ $0.186 \mathrm{mg} / \mathrm{dL}$ (95\% CI $-0.861,-0.116 ; p=0.011)$, as well as in the PPS: LS mean \pm SE of $-0.552 \pm 0.270 \mathrm{mg} / \mathrm{dL}(95 \% \mathrm{CI}$ $-1.098,-0.005 ; p=0.048$ ) (Table 2).

Analyses by age group showed reductions in serum phosphorus from baseline in all age group categories (Table 3); however, statistically significant reductions $(p=0.022)$ in serum phosphorus were achieved only in subjects aged $\geq 12$ to $\leq 18$ years. This finding was further confirmed by the post hoc analysis.

Among subjects in the SFOH group with serum phosphorus levels above age-related normal ranges at baseline $(n=$ $40)$, there were statistically significant reductions $(p=0.006)$ in serum phosphorus from baseline to the end of stage 1 (LS mean $\pm \mathrm{SE}-0.872 \pm 0.296 \mathrm{mg} / \mathrm{dL}[95 \% \mathrm{CI}-1.474$, $0.270]$ ), whereas no significant change was observed for subjects whose baseline phosphorus was within or below normal ranges $(n=25 ; \mathrm{LS}$ mean \pm SE $0.255 \pm 0.452 \mathrm{mg} / \mathrm{dL}[95 \%$ CI $-0.692,1.201])$. These results were confirmed by the post hoc analysis with LS mean \pm SE serum phosphorus reductions of $-0.942 \pm 0.246 \mathrm{mg} / \mathrm{dL}(95 \% \mathrm{CI}-1.440,-0.443 ; p=$ 0.0005 ) in SFOH subjects with serum phosphorus levels above age-related normal ranges at baseline, and no significant change in the $\mathrm{SFOH}$ subjects with baseline phosphorus within or below normal ranges: LS mean \pm SE of $0.208 \pm$ $0.232 \mathrm{mg} / \mathrm{dL}(95 \% \mathrm{CI}-0.277,0.692)$.

Greater reductions from baseline in serum phosphorus were observed in all age groups of subjects with higher baseline serum phosphorus levels. However, these were only statistically significant ( $p=0.001$ ) among subjects aged $\geq 12$ to $\leq 18$ years old (Supplementary Table 3 ).

\section{Secondary efficacy endpoints}

In the FAS, LS mean \pm SE change in serum phosphorus from baseline to the end of stage 1 for the CaAc group $(n=15)$ was $1.903 \pm 0.992 \mathrm{mg} / \mathrm{dL}(95 \% \mathrm{CI}-4.147,0.340 ; p=0.0872)$ based on the pre-defined statistical model and $-0.839 \pm 0.709 \mathrm{mg} / \mathrm{dL}$ (95\% CI $-2.418,0.741 ; p=0.264$ ) based on the post hoc analysis model. LS mean \pm SE change in serum phosphorus from baseline to the end of stage 2 was $+0.307 \pm 0.614 \mathrm{mg} / \mathrm{dL}$ ( $95 \%$ $\mathrm{CI}-0.947,1.560)$ in the SFOH group $(n=36)$ and $-1.218 \pm$ $0.676 \mathrm{mg} / \mathrm{dL}(95 \% \mathrm{CI}-9.804,7.369)$ in the CaAc group $(n=6)$.

Serum phosphorus levels displayed small but consistent decreases from baseline in the SFOH group throughout the study (Fig. 3), whereas fluctuations relative to baseline were observed with $\mathrm{CaAc}$, although the patient numbers in this group were small (Supplementary Fig. 2). In the FAS, the percentage of subjects in the SFOH group with serum phosphorus levels within age-related target ranges increased from $16.9 \%$ at baseline to $39.1 \%$ by the end of stage 1 , and to $35.0 \%$ by the end of stage 2 (Supplementary Fig. 3). Similar increases were also observed in the PPS population: $21.4 \%$ at baseline, $45.2 \%$ by the end of stage 1 , and $39.3 \%$ by the end of stage 2 .

\section{Treatment compliance}

Mean \pm SD treatment compliance during the overall study period (stage 1 and stage 2 ) in the safety population was $79.9 \pm 23.7 \%$ in the SFOH group and $62.6 \pm 37.9 \%$ in the $\mathrm{CaAc}$ group. Analyses by age group showed that median compliance with $\mathrm{SFOH}$ treatment during the overall study period ranged from $77.9 \%$ ( $\geq 12$ to $\leq 18$ years subgroup) to $93.3 \%$ ( $\geq 2$ to $<6$ years subgroup) (Supplementary Table 4 ).

\section{Safety}

The mean \pm SD duration of treatment exposure was longer in the $\mathrm{SFOH}$ group than in the $\mathrm{CaAc}$ group, both during stage 1 
Table 1 Baseline demographics and characteristics (FAS; $N=80$ )

\begin{tabular}{|c|c|c|}
\hline Parameter & $\mathrm{SFOH}(N=65)$ & $\mathrm{CaAc}(N=15)$ \\
\hline Mean \pm SD age at randomization, years & $12.1 \pm 4.10$ & $12.3 \pm 3.96$ \\
\hline $2-<6$ years, $n(\%)$ & $6(9.2)$ & $1(6.7)$ \\
\hline $6-12$ years, $n(\%)$ & $17(26.2)$ & $4(26.7)$ \\
\hline $12-\leq 18$ years, $n(\%)$ & $42(64.6)$ & $10(66.7)$ \\
\hline Male, $n(\%)$ & $31(47.7)$ & $5(33.3)$ \\
\hline Mean \pm SD body weight, $\mathrm{kg}$ & $42.1 \pm 18.1$ & $37.4 \pm 19.2$ \\
\hline \multicolumn{3}{|l|}{ Etiology of CKD, $n(\%)$} \\
\hline Congenital anomalies of the kidney and urinary tract & $19(29.2)$ & $3(20.0)$ \\
\hline Glomerulonephritis & $10(15.4)$ & $4(26.7)$ \\
\hline Hypodysplasia and reflux & $2(3.1)$ & $2(13.3)$ \\
\hline Obstructive uropathy & $8(12.3)$ & $1(6.7)$ \\
\hline Polycystic kidney disease & $3(4.6)$ & 0 \\
\hline Other & $23(35.4)$ & $5(33.3)$ \\
\hline \multicolumn{3}{|l|}{ CKD stage, $n(\%)$} \\
\hline 4 & $13(20.0)$ & $1(6.7)$ \\
\hline 5 & $52(80.0)$ & $14(93.3)$ \\
\hline \multicolumn{3}{|l|}{ Dialysis modality, $n(\%)$} \\
\hline Hemodialysis & $45(69.2)$ & $9(60.0)$ \\
\hline Peritoneal dialysis & $5(7.7)$ & $5(33.3)$ \\
\hline None & $15(23.1)$ & $1(6.7)$ \\
\hline \multicolumn{3}{|l|}{ Phosphate binder-naïve, $n(\%)$} \\
\hline Yes & $18(27.7)$ & $3(20.0)$ \\
\hline No & $47(72.3)$ & $12(80.0)$ \\
\hline \multicolumn{3}{|l|}{ Washout period needed, $n(\%)$} \\
\hline$n$ (missing) & $47(18)$ & $12(3)$ \\
\hline Yes & $7(14.9)$ & $4(33.3)$ \\
\hline No & $40(85.1)$ & $8(66.7)$ \\
\hline Mean (SD) baseline serum phosphorus, $\mathrm{mg} / \mathrm{dL}^{\mathrm{a}}$ & $6.41(1.62)$ & $6.67(2.07)$ \\
\hline
\end{tabular}

$C a A c$, calcium acetate; $C K D$, chronic kidney disease; $F A S$, full analysis set; $S D$, standard deviation; $S F O H$, sucroferric oxyhydroxide

${ }^{\text {a }}$ Serum phosphorus data are from central laboratory
(45.7 \pm 23.2 days vs. $37.8 \pm 28.4$ days, respectively) and the overall study ( $126.5 \pm 83.9$ days vs. $73.9 \pm 73.6$ days). Mean \pm SD average daily dose in the SFOH group was $1216.2 \pm$ $526.4 \mathrm{mg}$ iron during stage 1 and $1281.4 \pm 611.8 \mathrm{mg}$ iron for the overall study; in the CaAc group, mean average daily dose $\pm \mathrm{SD}$ was $12.4 \pm 8.1 \mathrm{~mL}$ during stage 1 and $12.3 \pm$ $8.8 \mathrm{~mL}$ for the overall study. The mean $\pm \mathrm{SD}$ prescribed average daily dose of SFOH during the overall study increased with age, ranging from $636.5 \pm 260.1 \mathrm{mg}$ iron, in subjects aged $\geq 2$ to $<6$ years, to $1798.9 \pm 483.9 \mathrm{mg}$ iron in subjects aged $\geq 12$ to $\leq 18$ years (Supplementary Table 4 ). The mean average daily number of tablets/powders taken by subjects was low and comparable across all age subgroups, ranging from 2.95 to 3.47 tablets/sachets per day. The mean \pm SD prescribed daily dose of CaAc also increased with age, although the number of patients in each age subgroup was small (Supplementary Table 5).
The proportion of subjects experiencing at least one TEAE was comparable between the groups for the overall study period (SFOH 75.8\% and CaAc 73.7\%) (Table 4). A summary of TEAEs occurring in $\geq 5 \%$ patients in either treatment group during the overall study is provided in Supplementary Table 6. The proportion of subjects experiencing at least one treatmentrelated TEAE during the overall study was comparable between treatment groups (SFOH 39.4\% subjects; CaAc $36.8 \%$ subjects). The most common treatment-related TEAEs occurred in the system organ class of GI disorders and metabolism and nutrition disorders (Supplementary Table 7). GI disorders considered related to study treatment were reported in $22(33.3 \%)$ subjects in the SFOH group and 4 $(21.1 \%)$ subjects in the CaAc group. The incidence of treatment-related TEAEs of diarrhea, discolored feces, and gastritis was higher in the $\mathrm{SFOH}$ group, while the incidence of nausea, abdominal pain, constipation, and upper abdominal 


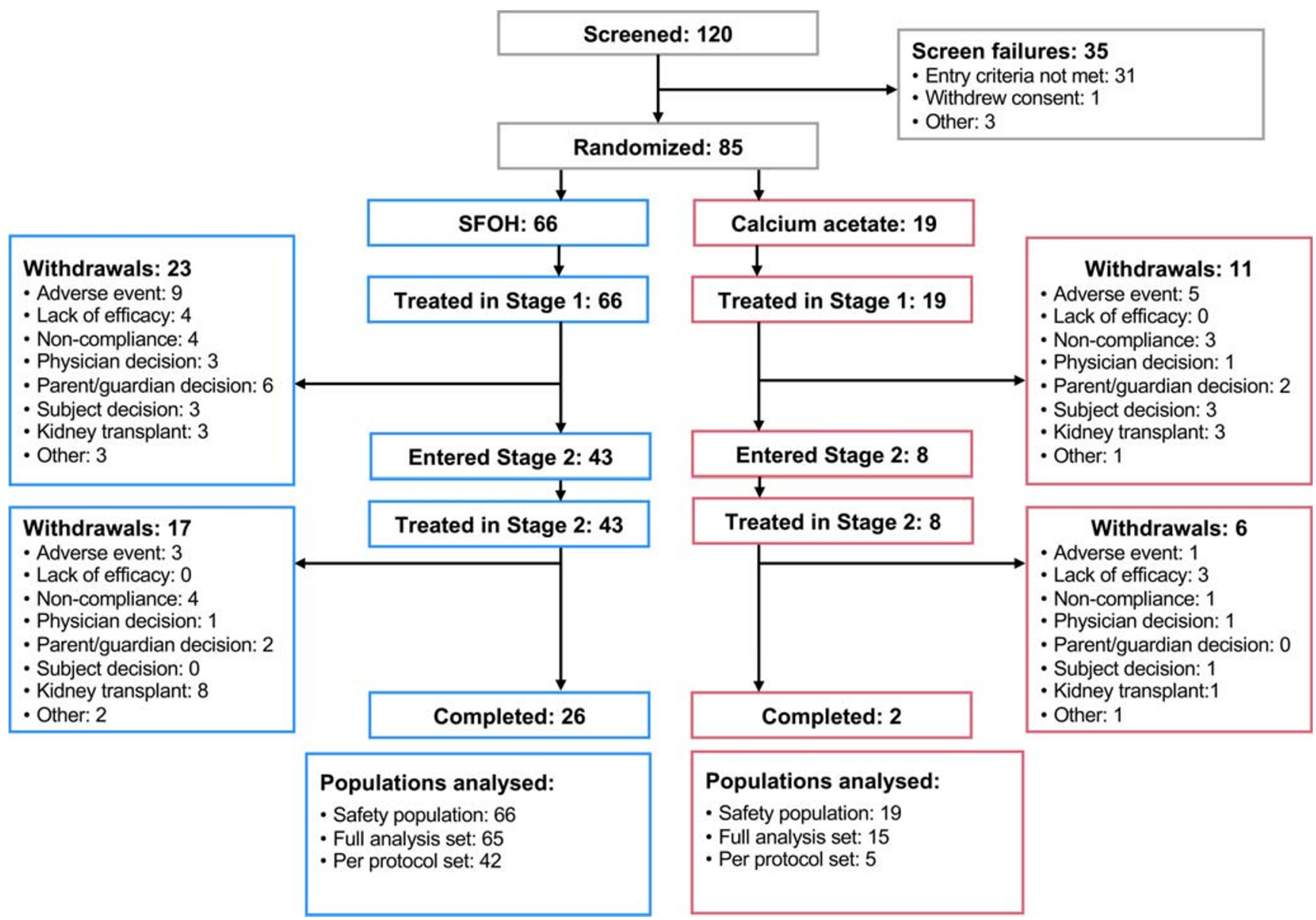

Fig. 2 Patient disposition (stage 1 and stage 2). SFOH, sucroferric oxyhydroxide. Note: More than one reason for study withdrawal may have been given for an individual subject

pain was higher in the CaAc group. No TEAEs leading to death were reported in either treatment group. The percentage of subjects with serious TEAEs was higher for SFOH (27.3\%) than for CaAc (15.8\%) during the overall study. Five serious TEAEs in 3 subjects, all in the SFOH group, were considered by the investigators as possibly related to study treatment: ileus ( 1 subject); gastritis (1 subject); and blood pressure increased, hypertension, and vena cava thrombosis (1 subject).

The proportion of patients who withdrew due to TEAEs was higher in the CaAc group $(n=6,31.6 \%)$ than in the SFOH group $(n=12,18.2 \%)$. Events that led to drug withdrawal in more than one subject in the $\mathrm{SFOH}$ group were diarrhea (6 subjects), nausea ( 2 subjects), and vomiting (2 subjects); those in the CaAc group were hypercalcemia (3 subjects) and hyperphosphatemia (2 subjects).

Changes in serum total corrected calcium, calciumphosphorus product, iPTH ferritin, and iron are shown in Supplementary Table 8. Changes from baseline in serum total corrected calcium were minimal in both treatment groups. The incidence of sustained hypercalcemia was higher in the $\mathrm{CaAc}$ group than in the $\mathrm{SFOH}$ group $(21.1 \%$ vs. $9.1 \%$ subjects experienced $\geq 1$ episode of sustained hypercalcemia during the study). Calcium-phosphorus product was lower and decreased from baseline to a greater extent in the $\mathrm{SFOH}$ group than in the $\mathrm{CaAc}$ group. No clinically meaningful changes from baseline in serum iPTH were observed in either group during the study. Observed mean changes from baseline in ferritin were similar between subjects in the $\mathrm{SFOH}$ and $\mathrm{CaAc}$ groups, with the caveat that approximately half of the patients were receiving oral or intravenous iron. Although some changes from baseline and individual deviations from the normal ranges were observed for other clinical laboratory parameters, including liver enzymes, vitamin levels, and bone markers (alkaline phosphatase and bone-specific alkaline phosphatase), they showed no trends or clinically relevant changes (data available on ClinicalTrials.gov).

\section{Discussion}

The aim of this phase 3 clinical trial was to investigate the safety and efficacy of SFOH in pediatric and adolescent patients with $\mathrm{CKD}$, and to provide dosing information for this patient population. 
Table 2 Change in serum phosphorus from baseline to end of stage 1 in the sucroferric oxyhydroxide group (FAS and PPS populations)
Table 3 Change in serum phosphorus level from baseline to end of stage 1 in the sucroferric oxyhydroxide group by age group (FAS population; $N=65$ )

\begin{tabular}{|c|c|c|}
\hline Parameter & FAS population $(n=65)$ & PPS population $(n=42)$ \\
\hline \multicolumn{3}{|l|}{ Baseline } \\
\hline Mean $\pm \mathrm{SD}, \mathrm{mg} / \mathrm{dL}$ & $6.45 \pm 1.698$ & $6.31 \pm 1.605$ \\
\hline \multicolumn{3}{|l|}{ End of stage 1} \\
\hline Mean $\pm \mathrm{SD}, \mathrm{mg} / \mathrm{dL}$ & $5.90 \pm 1.990$ & $5.68 \pm 2.106$ \\
\hline \multicolumn{3}{|c|}{ Change from BL to end of stage 1} \\
\hline Mean \pm SD & $-0.54 \pm 1.508$ & $-0.63 \pm 1.675$ \\
\hline \multicolumn{3}{|l|}{ Pre-defined model ${ }^{\mathrm{a}}$} \\
\hline $\mathrm{LS}$ mean $\pm \mathrm{SE}$ & $-0.371 \pm 0.251$ & $-0.433 \pm 0.388$ \\
\hline $95 \% \mathrm{CI}$ & $-0.874,0.132$ & $-1.220,0.353$ \\
\hline$p$ value ${ }^{\mathrm{b}}$ & 0.146 & 0.271 \\
\hline \multicolumn{3}{|l|}{ Post hoc model ${ }^{\mathrm{c}}$} \\
\hline $\mathrm{LS}$ mean $\pm \mathrm{SE}$ & $-0.488 \pm 0.186$ & $-0.552 \pm 0.270$ \\
\hline $95 \% \mathrm{CI}$ & $-0.861,-0.116$ & $-1.098,-0.005$ \\
\hline$p$ value $\mathrm{e}^{\mathrm{b}}$ & 0.011 & 0.048 \\
\hline
\end{tabular}

$B L$, baseline; $C I$, confidence interval; $F A S$, full analysis set; $L S$, least squares; $P P S$, per protocol set; $S D$, standard deviation; $S E$, standard error

${ }^{\text {a }}$ Results are obtained from a linear mixed model that includes change in serum phosphorus levels from baseline to the end of stage 1 as dependent variable and treatment, baseline serum phosphorus, age (in categories) at randomization, region (non-US/US), and gender as fixed effects (pre-defined statistical model)

${ }^{\mathrm{b}} p$ value for least squares means $t$ test is presented

${ }^{\mathrm{c}}$ Results are obtained from a linear mixed model which includes change in serum phosphorus levels from baseline to the end of stage 1 as dependent variable and treatment, baseline serum phosphorus, age at randomization, region (non-US/US), and gender as fixed effects (post hoc analysis)

\begin{tabular}{|c|c|c|c|}
\hline Parameter & $\begin{array}{l}\text { Age } \geq 2 \text { to }<6 \text { years } \\
(n=6)\end{array}$ & $\begin{array}{l}\text { Age } \geq 6 \text { to }<12 \text { years } \\
(n=17)\end{array}$ & $\begin{array}{l}\text { Age } \geq 12 \text { to } \leq 18 \text { years } \\
(n=42)\end{array}$ \\
\hline \multicolumn{4}{|l|}{ Baseline } \\
\hline $\begin{array}{l}\text { Mean } \pm S D \\
\mathrm{mg} / \mathrm{dL}\end{array}$ & $7.33 \pm 1.992$ & $6.93 \pm 1.883$ & $6.12 \pm 1.522$ \\
\hline \multicolumn{4}{|l|}{ End of stage 1} \\
\hline $\begin{array}{l}\text { Mean } \pm \text { SD } \\
\mathrm{mg} / \mathrm{dL}\end{array}$ & $7.09 \pm 1.924$ & $6.21 \pm 2.730$ & $5.61 \pm 1.578$ \\
\hline \multicolumn{4}{|c|}{ Change from $\mathrm{BL}$ to stage 1} \\
\hline Mean \pm SD & $-0.24 \pm 0.783$ & $-0.72 \pm 2.136$ & $-0.51 \pm 1.291$ \\
\hline \multicolumn{4}{|c|}{ Pre-defined model ${ }^{\mathrm{a}}$} \\
\hline $\mathrm{LS}$ mean $\pm \mathrm{SE}$ & $-0.243 \pm 0.380$ & $-0.620 \pm 0.489$ & $-0.460 \pm 0.192$ \\
\hline $95 \% \mathrm{CI}$ & $-1.450,0.965$ & $-1.675,0.436$ & $-0.850,-0.070$ \\
\hline$p$ value $\mathrm{e}^{\mathrm{b}}$ & 0.568 & 0.227 & 0.022 \\
\hline \multicolumn{4}{|l|}{ Post hoc model ${ }^{\mathrm{c}}$} \\
\hline $\mathrm{LS}$ mean $\pm \mathrm{SE}$ & $-0.243 \pm 0.405$ & $-0.608 \pm 0.498$ & $-0.460 \pm 0.195$ \\
\hline $95 \% \mathrm{CI}$ & $-1.986,1.501$ & $-1.694,0.478$ & $-0.856,-0.065$ \\
\hline$p$ value $\mathrm{e}^{\mathrm{b}}$ & 0.610 & 0.246 & 0.024 \\
\hline
\end{tabular}

$B L$, baseline; $C I$, confidence interval; $F A S$, full analysis set; $L S$, least squares; $S D$, standard deviation; $S E$, standard error

${ }^{a}$ Results are obtained from a linear mixed model that includes change in serum phosphorus levels from baseline to the end of stage 1 as dependent variable and treatment, baseline serum phosphorus, age (in categories) at randomization, region (non-US/US), and gender as fixed effects (pre-defined statistical model)

${ }^{\mathrm{b}} p$ value for least squares means $t$ test is presented

${ }^{\mathrm{c}}$ Results are obtained from a linear mixed model which includes change in serum phosphorus levels from baseline to the end of stage 1 as dependent variable and treatment, baseline serum phosphorus, age at randomization, region (non-US/US), and gender as fixed effects (post hoc analysis) 


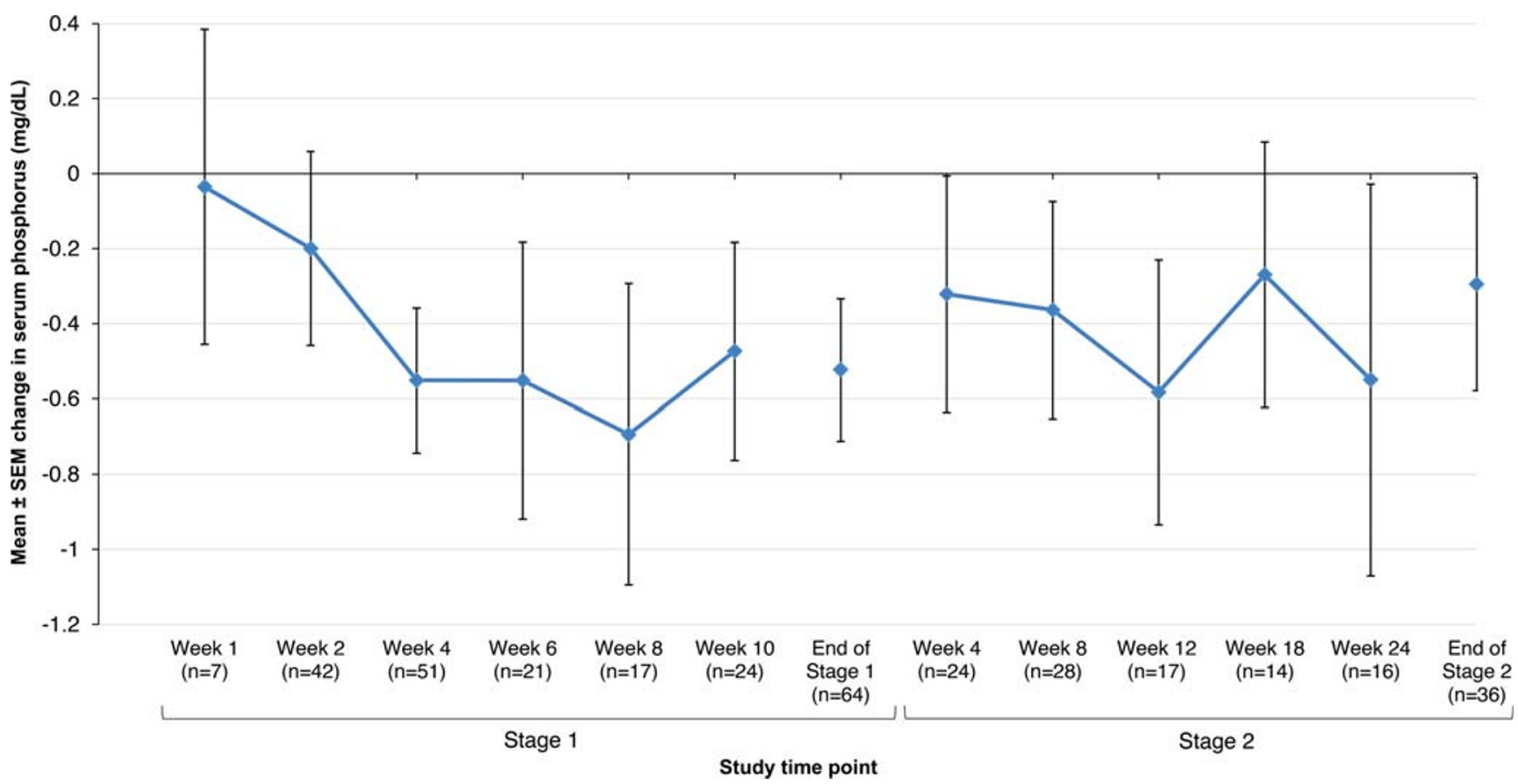

Fig. 3 Mean change ( \pm SEM) from baseline in serum phosphorus levels to end of stage 2 in the sucroferric oxyhydroxide group (FAS; $N=65)$. FAS, full analysis set; SEM, standard error of the mean. Data are from central laboratory

A calcium-based $\mathrm{PB}(\mathrm{CaAc})$ was chosen as an active control to provide comparisons of the serum phosphoruslowering effects and adverse event profile of SFOH with those of a PB commonly used in clinical practice. No formal comparison with $\mathrm{CaAc}$ was planned. The study planned to randomize approximately 130 subjects, but was prematurely ended due to challenges with patient recruitment, especially in patients below 9 years of age, and modification of study requirements, as agreed with the US Food and Drug
Administration (FDA) and the European Medicines Agency (EMA).

The adverse event profile of SFOH in pediatric and adolescent subjects with CKD was generally consistent with the known safety profile of SFOH and with previous experience in adults with kidney failure [21-23]. Most reported adverse events in the present study were characteristic of this patient population (i.e., related to dialysis or underlying concomitant diseases), or were consistent with the safety profile of $\mathrm{SFOH}$
Table 4 Overview of treatmentemergent adverse events in either treatment group during the study (safety population; $n=85$ )

\begin{tabular}{|c|c|c|c|c|}
\hline & \multicolumn{2}{|l|}{$\mathrm{SFOH}(N=66)$} & \multicolumn{2}{|l|}{$\mathrm{CaAc}(N=19)$} \\
\hline & Patients, $n(\%)$ & Events, $n$ & Patients, $n(\%)$ & Events, $n$ \\
\hline \multicolumn{5}{|l|}{ End of stage 1} \\
\hline Any TEAE & $42(63.6)$ & 123 & $13(68.4)$ & 46 \\
\hline Any treatment-related TEAE & $24(36.4)$ & 43 & $7(36.8)$ & 13 \\
\hline Any serious TEAE & $13(19.7)$ & 19 & $3(15.8)$ & 7 \\
\hline Any TEAE leading to death & 0 & 0 & 0 & 0 \\
\hline Any TEAE leading to study drug withdrawal & $11(16.7)$ & 17 & $6(31.6)$ & 8 \\
\hline \multicolumn{5}{|l|}{ End of stage 2} \\
\hline Any TEAE & $50(75.8)$ & 204 & $14(73.7)$ & 63 \\
\hline Any treatment-related TEAE & $26(39.4)$ & 50 & $7(36.8)$ & 13 \\
\hline Any serious TEAE & $18(27.3)$ & 43 & $3(15.8)$ & 9 \\
\hline Any TEAE leading to death & 0 & 0 & 0 & 0 \\
\hline Any TEAE leading to study drug withdrawal & $12(18.2)$ & 19 & $6(31.6)$ & 8 \\
\hline
\end{tabular}

$C a A C$, calcium acetate; $S F O H$, sucroferric oxyhydroxide; TEAE, treatment-emergent adverse event 
in adults. No new safety signals were identified, compared with the adult population, and no clear safety difference was observed between age groups; however, the number of subjects in the younger age groups was small. Diarrhea was reported as a treatment-related TEAE in $16.7 \%$ of subjects randomized to SFOH. This observation is consistent with phase 2 and phase 3 clinical trials of SFOH in adults [21-23], although the reporting rate of $11.6 \%$ in the pooled adult studies [28] was slightly lower than that seen in this pediatric study. The majority of diarrhea events were graded as mild or moderate in intensity, which is consistent with the typical safety profile for adults. Other than diarrhea, no other treatment-related TEAE was reported as "very common" ( $\geq 10 \%$ frequency). The percentage of withdrawals due to TEAEs was lower in the SFOH group than in the CaAc group.

The analysis of efficacy in the overall SFOH group (primary endpoint) using the pre-defined statistical model did not show statistical significance; this model was not the most appropriate given the dichotomization of subject age and imbalanced age categories, which reduced the observed treatment effect size. Statistically significant reductions in serum phosphorus were observed in a post hoc analysis using a statistical model that took into account the imbalance of age categories; the post hoc analysis findings provide an accurate reflection of the treatment effect with SFOH in this study population.

Overall, reductions in serum phosphorus levels were observed with $\mathrm{SFOH}$ in all age groups evaluated; however, a statistically significant reduction was observed only in the subgroup of subjects aged $\geq 12$ to $\leq 18$ years. A clinically important and statistically significant decrease in serum phosphorus from baseline to the end of stage 1 was observed in the subgroup of SFOH subjects who had serum phosphorus above the age-related normal range at baseline, but not in the subgroup with serum phosphorus within or below the age-related normal range at baseline. The last group accounted for 25/65 (38.5\%) subjects in the SFOH group, which may have reduced the magnitude of the serum phosphorus-lowering effect observed in the overall SFOH group. Subgroup analysis by both age group and baseline serum phosphorus level showed statistically significant reductions in serum phosphorus levels among subjects aged $\geq 12$ to $\leq 18$ years old with baseline phosphorus above age-related normal ranges, but not among subjects in the same age group with baseline levels below or within normal ranges. The statistically significant reductions in serum phosphorus in subjects with serum phosphorus levels at baseline above the age-related normal range are consistent with results observed for sevelamer carbonate in pediatric patients [29]. However, the median dose of sevelamer carbonate in this study was 8 to 9 tablets per day.

Certain aspects of the study design probably contributed to the efficacy findings by reducing the observed treatment effect. There was overlap between the target serum phosphorus levels required for randomization per protocol (during the washout period) and the post-randomization target range. Consequently, it was possible for subjects to have had serum phosphorus levels within the post-randomization target ranges after little or no change from their baseline levels. Furthermore, the study protocol allowed a direct switch of PB without a washout period for subjects who had serum phosphorus levels above the threshold required for randomization ( $>80 \%$ of patients in the study received a prior PB treatment). Therefore, for most patients who were not PB-naïve, the efficacy of SFOH was being compared to the patient's pre-study binder therapy.

Treatment compliance was probably an additional contributor to the effect of SFOH on serum phosphorus. Nonadherence to treatment is an important determinant of $\mathrm{PB}$ treatment efficacy [30,31], and was a common protocol deviation in the SFOH treatment group, identified for $27.7 \%$ of subjects in the FAS.

The efficacy of SFOH in reducing serum phosphorus levels was previously confirmed in global clinical studies in adult CKD patients on dialysis $[21,22]$. The mechanism of action of SFOH is based on the binding of phosphate in the GI tract, and there is no reason to expect differences between adults and children with respect to phosphate binding. The present study confirms that SFOH works in the pediatric population. A significant treatment effect was observed in adolescents $(\geq$ 12 to $\leq 18$ years); in the younger age groups, the numeric trends were similar, but the small patient numbers made it challenging to demonstrate a statistically significant decrease of serum phosphorus in the younger patients.

Despite the limitations of this study, the results demonstrate the overall efficacy of SFOH for reducing serum phosphorus in the pediatric population and maintaining age-appropriate serum phosphorus levels; the proportion of subjects achieving serum phosphorus levels within the age-related target range increased more than twofold from baseline to the end of stage 1 and stage 2 .

Studies of adults with $\mathrm{CKD}$ have demonstrated that $\mathrm{SFOH}$ is effective for lowering serum phosphorus and achieves this with a low daily pill burden. This low pill burden was confirmed in the current pediatric study (Supplementary Table 4), and may increase long-term adherence compared to other PBs.

\section{Conclusions}

Overall, the safety profile of SFOH in pediatric and adolescent subjects with CKD was comparable to that previously observed in adult subjects with kidney failure. No new safety signals were identified in the pediatric and adolescent populations. Serum phosphorus-lowering trends were observed in all age groups. Statistically significant reductions in serum phosphorus with SFOH were observed in adolescent subjects aged $\geq 12$ to $\leq 18$ years old, and in the group of subjects with baseline serum phosphorus levels above age-related normal ranges. SFOH demonstrated a positive benefit-risk profile in 
the pediatric population with a low pill burden, and the results of this study support for the use of SFOH in pediatric and adolescent CKD patients with hyperphosphatemia.

Acknowledgments This study was sponsored by Vifor Fresenius Medical Care Renal Pharma France. We thank all investigators and teams participating in this study, the patients and their families. Medical writing assistance was provided by AXON Communications, London, UK.

\section{Compliance with ethical standards}

Conflict of interest Larry A. Greenbaum and Günter Klaus have served as consultants for Vifor Pharmaceuticals. Larysa Wickman has served as a consultant for Novartis Pharma. Amandine Perrin and Milica Enoiu are employees of Vifor Pharma.

Open Access This article is licensed under a Creative Commons Attribution 4.0 International License, which permits use, sharing, adaptation, distribution and reproduction in any medium or format, as long as you give appropriate credit to the original author(s) and the source, provide a link to the Creative Commons licence, and indicate if changes were made. The images or other third party material in this article are included in the article's Creative Commons licence, unless indicated otherwise in a credit line to the material. If material is not included in the article's Creative Commons licence and your intended use is not permitted by statutory regulation or exceeds the permitted use, you will need to obtain permission directly from the copyright holder. To view a copy of this licence, visit http://creativecommons.org/licenses/by/4.0/.

\section{References}

1. Hruska KA, Mathew S, Lund R, Qiu P, Pratt R (2008) Hyperphosphatemia of chronic kidney disease. Kidney Int 74: $148-157$

2. Kidney Disease: Improving Global Outcomes CKD-MBD Working Group (2009) KDIGO clinical practice guideline for the diagnosis, evaluation, prevention, and treatment of chronic kidney disease-mineral and bone disorder (CKD-MBD). Kidney Int Suppl: S1-S130

3. Block GA, Hulbert-Shearon TE, Levin NW, Port FK (1998) Association of serum phosphorus and calcium $\mathrm{x}$ phosphate product with mortality risk in chronic hemodialysis patients: a national study. Am J Kidney Dis 31:607-617

4. Block GA, Klassen PS, Lazarus JM, Ofsthun N, Lowrie EG, Chertow GM (2004) Mineral metabolism, mortality, and morbidity in maintenance hemodialysis. J Am Soc Nephrol 15:2208-2218

5. Ganesh SK, Stack AG, Levin NW, Hulbert-Shearon T, Port FK (2001) Association of elevated serum $\mathrm{PO}(4), \mathrm{Ca} \times \mathrm{PO}(4)$ product, and parathyroid hormone with cardiac mortality risk in chronic hemodialysis patients. J Am Soc Nephrol 12:2131-2138

6. Hutchison AJ, Smith CP, Brenchley PE (2011) Pharmacology, efficacy and safety of oral phosphate binders. Nat Rev Nephrol 7: 578-589

7. Moe S, Drüeke T, Cunningham J, Goodman W, Martin K, Olgaard K, Ott S, Sprague S, Lameire N, Eknoyan G (2006) Definition, evaluation, and classification of renal osteodystrophy: a position statement from kidney disease: improving global outcomes (KDIGO). Kidney Int 69:1945-1953

8. Kendrick J, Kestenbaum B, Chonchol M (2011) Phosphate and cardiovascular disease. Adv Chronic Kidney Dis 18:113-119
9. Hanudel MR, Salusky IB (2017) Treatment of pediatric chronic kidney disease-mineral and bone disorder. Curr Osteoporos Rep 15:198-206

10. Wingen AM, Fabian-Bach C, Schaefer F, Mehls O (1997) Randomised multicentre study of a low-protein diet on the progression of chronic renal failure in children. European Study Group of Nutritional Treatment of Chronic Renal Failure in Childhood. Lancet 349:1117-1123

11. Salusky IB, Coburn JW, Foley J, Nelson P, Fine RN (1986) Effects of oral calcium carbonate on control of serum phosphorus and changes in plasma aluminum levels after discontinuation of aluminum-containing gels in children receiving dialysis. J Pediatr 108:767-770

12. Alon U, Davidai G, Bentur L, Berant M, Better OS (1986) Oral calcium carbonate as phosphate-binder in infants and children with chronic renal failure. Miner Electrolyte Metab 12:320-325

13. Goodman WG, Goldin J, Kuizon BD, Yoon C, Gales B, Sider D, Wang Y, Chung J, Emerick A, Greaser L, Elashoff RM, Salusky IB (2000) Coronary-artery calcification in young adults with end-stage renal disease who are undergoing dialysis. N Engl J Med 342: $1478-1483$

14. Hill KM, Martin BR, Wastney ME, McCabe GP, Moe SM, Weaver CM, Peacock M (2013) Oral calcium carbonate affects calcium but not phosphorus balance in stage 3-4 chronic kidney disease. Kidney Int 83:959-966

15. Oh J, Wunsch R, Turzer M, Bahner M, Raggi P, Querfeld U, Mehls O, Schaefer F (2002) Advanced coronary and carotid arteriopathy in young adults with childhood-onset chronic renal failure. Circulation 106:100-105

16. Renagel $®$ (sevelamer hydrochloride). Highlights of prescribing information. Last accessed: 24 November 2019. Available from: http://products.sanofi.us/Renagel/Renagel.pdf

17. Renvela $₫($ sevelamer carbonate) Highlights of prescribing information. Last accessed: 24 November 2019. Available from: http:// products.sanofi.us/Renvela/Renvela.pdf

18. Haratake J, Yasunaga C, Ootani A, Shimajiri S, Matsuyama A, Hisaoka M (2015) Peculiar histiocytic lesions with massive lanthanum deposition in dialysis patients treated with lanthanum carbonate. Am J Surg Pathol 39:767-771

19. Makino M, Kawaguchi K, Shimojo H, Nakamura H, Nagasawa M, Kodama R (2015) Extensive lanthanum deposition in the gastric mucosa: the first histopathological report. Pathol Int 65:33-37

20. Zhang C, Wen J, Li Z, Fan J (2013) Efficacy and safety of lanthanum carbonate on chronic kidney disease-mineral and bone disorder in dialysis patients: a systematic review. BMC Nephrol 14:226

21. Floege J, Covic AC, Ketteler M, Mann JF, Rastogi A, Spinowitz B, Chong EM, Gaillard S, Lisk LJ, Sprague SM, Sucroferric Oxyhydroxide Study Group (2015) Long-term effects of the ironbased phosphate binder, sucroferric oxyhydroxide, in dialysis patients. Nephrol Dial Transplant 30:1037-1046

22. Floege J, Covic AC, Ketteler M, Rastogi A, Chong EM, Gaillard S, Lisk LJ, Sprague SM, PA21 Study Group (2014) A phase III study of the efficacy and safety of a novel iron-based phosphate binder in dialysis patients. Kidney Int 86:638-647

23. Wuthrich RP, Chonchol M, Covic A, Gaillard S, Chong E, Tumlin JA (2013) Randomized clinical trial of the iron-based phosphate binder PA21 in hemodialysis patients. Clin J Am Soc Nephrol 8: 280-289

24. World Medical Association (2013) World Medical Association Declaration of Helsinki: ethical principles for medical research involving human subjects. JAMA 310:2191-2194

25. International Council for Harmonization (ICH) E6 Guideline for good clinical practice (GCP). Last accessed: 24 November 2019. Available from: https:/www.ema.europa.eu/en/ich-e6-r2-goodclinical-practice 
26. Schwartz GJ, Muñoz A, Schneider MF, Mak RH, Kaskel F, Warady BA, Furth SL (2009) New equations to estimate GFR in children with CKD. J Am Soc Nephrol 20:629-637

27. Langman CB, Salusky IB, Greenbaum LA, Jueppner H, Leonard M, Nelson P, Portale A, Warady BA (2005) K/DOQI clinical practice guidelines for bone metabolism and disease in children with chronic kidney disease. Am J Kidney Dis 46(Supplement 1):S1S121

28. VELPHORO (sucroferric oxyhydroxide). Summary of product characteristics Last accessed: 24 November 2019. Available at: https://www.ema.europa.eu/en/documents/product-information/ velphoro-epar-product-information_en.pdf

29. Fathallah-Shaykh S, Drozdz D, Flynn J, Jenkins R, WesselingPerry K, Swartz SJ, Wong C, Accomando B, Cox GF, Warady
BA (2018) Efficacy and safety of sevelamer carbonate in hyperphosphatemic pediatric patients with chronic kidney disease. Pediatr Nephrol 33:325-333

30. Arenas MD, Malek T, Gil MT, Moledous A, Alvarez-Ude F, ReigFerrer A (2010) Challenge of phosphorus control in hemodialysis patients: a problem of adherence? J Nephrol 23:525-534

31. Covic A, Rastogi A (2013) Hyperphosphatemia in patients with ESRD: assessing the current evidence linking outcomes with treatment adherence. BMC Nephrol 14:153

Publisher's note Springer Nature remains neutral with regard to jurisdictional claims in published maps and institutional affiliations. 